\section{O feedback possível: a relação do jornal on-line com 0 impresso ${ }^{1}$}

\section{RESUMO}

Este trabalho analisa a relação do jornal on-line com o jornal impresso, levando-se em consideração a participação do leitor. A pesquisa pretende saber se 0 impresso vem sofrendo alterações, atualizando-se e utilizando as sugestões de leitores virtuais, diante da participação destes por e-mail.

\begin{abstract}
This paper refers to the relations between on-line newspapers and printed newspapers, taking into consi-deration the role of the reader. The research intends to find out whether the printed newspaper has been undergoing changes, as sugested by readers through e-mail.
\end{abstract}

\section{PALAVRAS-CHAVE (KEY WORDS) \\ - Jornalismo e tecnologia (Journalism and technology) \\ - Interatividade (Interactivity) \\ - Jornais on-line (On-line newspapers)}

\section{Heloisa Juncklaus Preis Moraes \\ Doutoranda em Comunicação - FAMECOS/PUCRS}

\section{O novo cenário da comunicação}

É impressionante a velocidade com que as coisas vêm mudando, principalmente quando se fala em meios de comunicação. Tempo e distância não são mais problemas. Mensagens e informações são enviadas ou recebidas de qualquer lugar do mundo em questão de segundos. Nota-se, cada vez com mais intensidade, as novas tecnologias influenciando a vida das pessoas. Não obstante, a comunicação de massa está se servindo destes avanços para tornar a informação mais rápida e ágil. Novos equipamentos, novas técnicas, novos meios. Estamos diante de uma revolução tecnológica que, se não acompanharmos, iremos ficando distantes, para trás. As previsões são ainda mais impressionantes e, por vezes, inacreditáveis. Tanto quanto foi, um dia, a televisão.

Tendo em vista todas as transformações que as novas tecnologias têm provocado nas formas de comunicação, bem como na construção e compartilhamento do conhecimento, não podemos negar que têm mudado também a socialidade humana.

Mesmo diante da difusão das tecnologias, o homem necessita integrarse a seus semelhantes, a seus grupos sociais. Uma parceia da vida em sociedade, premissa do surgimento da comunicação, é imprescindível ao homem. Negar o progresso e a ciência é tolice. Mas querer isolar o homem em u mundo virtual, individualizando-o, é crueldade. As novas tecnologias comunicacionais são alternativas de divulgação de um trabalho feito em conjunto. E só a efetiva 
participação fará com que não se dividam, mais uma vez, as pessoas em ricos e pobres, agora de informação.

Se, por um lado, as novas tecnologias podem auxiliar o processo de produção aumentando a qualidade e a rapidez, e, de outro, o homem precisa da vida em comunidade, por que não uni-los? Assim, pretendemos resgatar a comunicação como forma de integração, manutenção de valores e culturas e (re) aproximação dos homens. Um processo participativo de que o homem precisa para sentir-se um ser social: que pensa, reflete, discute, fala, tem objetivos, toma decisões, tem amigos e desfruta de um sentimento de solidariedade. É possível utilizar essas tecnologias sem a ameaça da solidão gerada pela relação homem-máquina? Um processo participativo, que envolva as pessoas, tem como conseqüência o engrandecimento do homem enquanto ser social, da comunidade em que ele vive tanto quanto da própria ciência Comunicação. Afinal, o processo comunicacional evoluiu não porque os homens queriam ficar sozinhos. Ao contrário, queriam participar de uma vida social.

O fazer jornalismo está mudando, está passando por transformações profundas e encontra-se em franco processo de renovação de muitas de suas práticas. Diante das transformações e do aprimoramento das técnicas e dos equipamentos do processo comunicativo e, ainda, da veloz assimilação das ferramentas da internet, a comunicação revela-se mais fácil, mais rápida, mais barata... Se para participar com críticas ou sugestões a um jornal era preciso escrever uma carta, colocar nos Correios, pagar, esperar a entrega (talvez atrasada), hoje, ao escrever um e-mail, as barreiras foram quebradas. Há, e esta já é uma hipótese, muito mais participação do leitor no jornal, a qual inclui também a sugestão de pautas. O problema considerado ou verificado nesta pesquisa é a relação do jornal on-line com o jornal impresso.
Segundo Ana Dalva², de O Globo, o "e-mail dá a pulsação das sensações dos leitores". Também Anabela Rebelato ${ }^{3}$, de $\mathrm{O}$ Estado de São Paulo, fala das mudanças da relação jornalxleitor com a chegada do e-mail. "Há maior participação, 'esquentou' muito a seção de cartas. Há mais agilidade na publicação, instantaneidade na resposta.... É uma necessidade do leitor de exercitar sua cidadania."

A pesquisa buscou saber se, através da sua versão on-line, logo da participação do leitor, o jornal impresso vem sofrendo alterações, atualizando-se e utilizando sugestões de leitores virtuais. Aliás, esta era uma outra hipótese, os jornais impressos também têm se beneficiado com o on-line. A versão virtual deveria aproveitar as disponibilidades e ferramentas para aprofundar as matérias, atualizá-las durante todo o dia, mas tem sido apenas um espelhamento ${ }^{4}$ do impresso. Diante da participação do leitor por e-mail, é o impresso que primeiro acata a sugestão. É uma relação de reatroalimentação.

$\mathrm{Na}$ versão impressa, os jornais caracterizam-se pela ênfase regional/local, principalmente no que diz respeito ao seu público-alvo. Essa característica perde-se no on-line, uma vez que não se sabe quem e de onde está acessando as informações. Nessa mudança de espaço (suporte), o jornal que vivia com limitações materiais passa a usufruir de um sistema ilimitado, híbrido. Leitores no exterior, por exemplo, podem estar a par dos fatos que ocorrem em sua região, mesmo estando a milhares de quilômetros. $\mathrm{E}$ mais, podem sugerir matérias que gostariam de ler. Há, realmente, mudanças.

A pesquisa realizada constituiuse em uma tentativa de conhecer melhor a transformação que o mundo da comunicação está passando no atual contexto das novas tecnologias, tendo em vista se tratar de um assunto paradoxalmente novo e muito falado. Tem-se ouvido falar, também, que com a possibilidade do jornal virtual a versão 
impressa está fadada à morte. Para a certificação das hipóteses, foi necessário um estudo mais aprofundado, uma pesquisa científica. $O$ trabalho desenvolveuse à luz da sociologia compreensiva, a qual "descreve a vivência pelo que ela é, contendo-se em discernir desta forma as intenções visadas pelos atores envolvidos" (Maffesoli, 1987: 15).

Para o confronto entre os argumentos teóricos e práticos abordados, foi realizada uma pesquisa de campo em dois jornais diários que mantêm veiculação virtua e impressa: Diário do Sul, de Tubarão, e Jornal da Manhã, de Criciúma, em Santa Catarina. Essa pesquisa de campo concretizou-se através de entrevistas com os editores e da análise dos e-mails recebidos pelos jornais, no período de $1^{\circ}$ a 15 de agosto de 2001, o que resultou na leitura interpretativa, aproximadamente, de dois mil e-mails, uma vez que o diário tubaronense recebe, em média, 80 e-mails por dia e, o criciumense, 50 . Os dois jornais são responsáveis pela circulação em duas importantes regiões do sul de Santa Catarina.

A relação entre os dois suportes: impresso e on-line

A pesquisa foi uma oportunidade de estudar e verificar todos os questionamentos iniciais. Para confrontar os dados teóricos com a prática, fizemos uma pesquisa de campo com dois jornais diários locais que mantêm veiculação on-line, de duas maneiras: análise de e-mails recebidos pelo jornal (no período de $1^{\circ}$ a 15 de agosto de 2001) e entrevista com os respectivos editores. Ambas realizadas e analisadas de acordo com categorias preestabelecidas.

Em se tratando de uma pesquisa com jornais locais, não podemos estender as conclusões aos demais tipos de veículos que têm veiculação impressa e on-line, uma vez que, como citado na história dos veículos pesquisados, eles possuem características próprias. Essa é a delimitação do trabalho.

Ao estudar os jornais nas versões impressa e virtual, queríamos visualizar a relação que está se estabelecendo entre elas. O jornal impresso vai mesmo acabar? Essa era a pergunta inicial. Após as pesquisas teórica e de campo, chegamos a algumas considerações que podem servir de iniciais a novas pesquisas.

Os dois jornais estão, segundo seus editores, totalmente voltados para a região de cobertura. As notícias priorizadas são as da região, sendo que as pautas nacionais focalizam a realidade local.

$\mathrm{Na}$ teoria e nas possibilidades oferecidas pela rede, a versão eletrônica seria uma veiculação mais aprofundada, completa e atualizada, uma vez que não encontra problemas quanto ao espaço e ao tempo. Na prática, pelo menos nos jornais estudados, não é o que ocorre. O jornal online é um espelhamento do impresso, ou seja, é uma transferência de matérias de uma versão para a outra.

A participação dos leitores no jornal, servindo como um feedback para este, é muito clara, como percebemos nas entrevistas com os editores e na análise dos e-mails dos leitores. Estes participam sugerindo pauta, criticando, elogiando, denunciando, escrevendo artigos e assim por diante. As manifestações são as mais variadas, predominando a sugestão de pauta, uma vez que o leitor espera que um problema seu ou de seu grupo seja resolvido pelo jornal.

Há uma verdadeira conversação social, em que as pessoas "comuns" podem participar da elaboração desse discurso encarado como "oficial". Essa participação ficou maior e mais dinâmica com a possibilidade do e-mail, principalmente em relação às cartas. Muitos leitores, principalmente da região, ainda utilizam o telefone. Essa participação tão efetiva dá-se pela identificação do leitor com as informações veiculadas pelos jornais: são relativas ao lugar com o qual eles têm uma 
relação real ou simbólica. Isso porque, mesmo jogado na rede, o jornal tem um público potencial que não é o mundo todo. Também porque já vimos que as afinidades são eletivas, e aqueles que se interessam pela versão on-line são os mesmos que provavelmente se interessariam (ou se interessam) pela versão impressa.

Os jornais, por sua vez, priorizam todas as manifestações e contatos do leitor, conferindo as informações e publicandoas, uma vez que isso também o favorece quanto às suas pretensões junto ao público-alvo. Também não podemos esquecer que um jornal é uma empresa e apostar no social, em alguns casos, pode ser um instrumento de marketing, um jogo de cena.

Há uma grande participação do leitor distante da região cujo contato com o jornal acontece através da sua versão on-line. As manifestações são as mesmas, querem informações, sugerem pautas, elogiam. Assim, podemos concluir que o jornal online serve como um "aproximador" do leitor com sua região, confirmando a teoria de que o homem precisa integrar-se aos seus semelhantes, aos grupos com os quais ele se identifica. Estes leitores dividemse por cidades do Estado em que não há circulação dos jornais estudados, outros Estados e até do exterior.

$\mathrm{Na}$ entrevista com os editores dos jornais que dispõe das duas formas de veiculação, verificamos que a relação entre jornal impresso e on-line é de complementação, confirmando a retroalimentação. As sugestões proporcionadas pelo jornal on-line são sempre acatadas primeiramente pelo impresso. Para eles, não há disputa ou concorrência, são veiculações diferentes (ou precisam ser), cada qual com suas características e que devem ser exploradas pelo que uma oferece de melhor em relação à outra.

Sobre isso, podemos citar o caso do colunista Cláudio Humberto, que dispõe de uma coluna atualizada diariamente na internet com informações sobre os bastidores da política e do poder em Brasília. Inicialmente, a coluna era veiculada apenas na versão virtual. Devido ao sucesso e ao número de acessos, sentiu-se a necessidade de transpô-la também para o suporte impresso em vários jornais do país. É um exemplo de como a informação pode fazer o caminho inverso: do on-line para o impresso, fortalecendo a sua veiculação.

Apesar dos bons resultados quanto à participação e ao feedback do leitor para o jornal, os editores ainda reclamam que há espaço maior para esse tipo de manifestação. Todavia, isso não é uma competência única e exclusiva do leitor, há de se construir estruturas, espaços e respostas que possibilitem essa interação. Segundo Braga (in Neto, 2001: 133), uma boa interatividade social em torno dos produtos midiáticos solicita: "a) produtos com estruturações eficientes para seus objetivos interativos; e b) produtores e receptores (a sociedade em geral) com competências bem desenvolvidas para interagir - de suas respectivas posições - com estes produtos".

\section{Considerações finais}

A evolução da comunicação corresponde, podemos dizer, à própria evolução da humanidade, ou vice-versa. Foi o domínio dos sistemas de comunicação, mesmo primitivos, que permitiu o desenvolvimento de relações, mitos, lendas, hábitos, regras, tecnologia, explicações, enfim, da vida. Desde os sinais, da fala, da escrita, da impressão, até se chegar aos meios de comunicação de massa, muito mudou. $O$ conhecimento de todas essas fases ou eras possibilita a compreensão de como o homem vivia, de como ele evoluiu e de como a comunicação foi determinante para essa evolução. Cada uma delas está relacionada com a vida diária das pessoas de uma época específica. Isso é tanto 
verdade para os anos dourados do rádio como para os hieróglifos criados pelos egípcios.

Logo, as inovações que se percebem atualmente levam à mesma mudança de comportamento humano que já ocorreu ao ler um jornal, ouvir um rádio, ir ao cinema ou assistir à televisão. Todos permanecem, entretanto abrem espaço para outros meios como se nota através da história.

Agora, são inúmeras as opções de transmissão de informação. Os meios e as técnicas são vários. Satélite, TV a cabo, computador, internet,... O jornal ganhou novo formato, pode ser lido on-line, em hipertexto, a distância, a qualquer hora.

O importante é repensar o papel da comunicação diante de tantas oportunidades. A concepção de comunicação a que este trabalho deu ênfase foi a de uma relação entre pessoas ou grupos que repartem experiências, conhecimentos, sentimentos e anseios. Neste processo comunicativo, todos têm oportunidade de contribuir, de ser emissores e receptores. Especificamente, falamos do ciberespaço, uma volta às tribos, que são escolhidas conforme a necessidade ou desejo, são eletivas. Interagem por identificações, sejam elas quais forem.

As novas tecnologias são importantes, mas como ferramentas auxiliares no processo de produção e não como substitutas das relações, do contato, da vida em grupo. O perigo está na individualização, no isolamento frente a um computador. Unanimidade sobre essa sociedade da informação também não existe, o que não podemos negar é que a informação atingiu um patamar significante na sociedade contemporânea.

O homem é um ser social que precisa estar em contato com as pessoas. A comunicação serve para isso: aproximálas e fazê-las crescer. Todos, a partir do nascimento, pertencem a grupos sociais que pressupõem pessoas numa relação mútua e organizada, com idéias e objetivos. Atingi-los implica tarefas, regras, comunicação e o próprio desenvolvimento do grupo. O ser humano não consegue viver só. Ele precisa trocar idéias, participar de ações, estar com alguém, enfim, viver em comunidade, como vimos nas palavras do sociólogo Maffesoli. Isso tudo reforçado pela possibilidade de estar perto, mesmo estando longe, como é o caso do contato de pessoas distantes com a sua região através de jornais on-line.

Não é a tecnologia por si só que irá nos livrar das mazelas, dos sentimentos mesquinhos e irritantes de uma sociedade hipócrita. A internet é uma ferramenta utilizada pelos homens e seus desejos, talvez os mesmos que hoje detêm o poder nas redes de televisão, rádio ou jornal. Mas também pode estar nas minhas mãos ou nas suas. Vale aproveitar a oportunidade.

$\mathrm{Na}$ teoria, a internet traz muitas novas possibilidades que, na prática, não foram tão rapidamente absorvidas (vejamos as possibilidades não utilizadas pela versão virtual dos jornais estudados). Já trouxe muitas mudanças e facilidades, é certo. Que nos digam todos aqueles que têm acesso. Porém, não podemos deixar de falar na imensa maioria da humanidade que não conta com estrutura e conhecimento suficientes para tomá-la como ferramenta.

Enquanto podemos estar em dúvida entre ler um jornal impresso ou on-line, há aqueles que esperam por um prato de comida. A desigualdade social alcança o patamar da informação, e como esta é poder, estamos ampliando ainda mais a fenda que divide os ricos e os pobres. Além das distâncias simbólicas, temos também as distâncias reais. Além dos obstáculos técnicos, temos agora que enfrentar os obstáculos de caráter socioeconômico e cultural.

A realidade de hoje inclui o ciberespaço. Não podemos nos posicionar em um dos extremos: triunfalismo ou negação. Fora esse determinismo tecnológico, temos que agir, integrar, estudar, fazer a nossa parte. Muitos 
dizem que ainda na pré-história da era digital é difícil estudar o que está acontecendo, porque estamos no meio das transformações. $O$ pesquisador e o objeto pesquisado fazem parte de um mesmo contexto histórico. Mas não esperemos para ver o que pode acontecer. Podemos começar a entender desde já.

Tecnicamente, a internet é o meio do possível, esperança de novos espaços de criação, de argumentação. Melhor se for um espaço público de troca, discussão e construção. O contato com o jornal, interatividade no sentido de criar junto, é um desses espaços. É o feedback possível através das sugestões dos leitores.

\section{Notas}

10 presente artigo apresenta resultados obtidos na dissertação, de mesmo título, defendida em dezembro de 2001 no Programa de Pós-Graduação da Famecos - PUCRS, sob orientação do Prof. Dr. Juremir Machado da Silva.

2 Em entrevista ao programa $N$ de Notícia, na Globo News, em 07/01/2001, às 23 horas.

3 Idem.

4 Neste caso, as matérias da versão on-line apresentamse tais e quais as da versão impressa. São as mesmas matérias, sem aprofundamento, atualização ou linguagem diferenciada. 0 termo refere-se ao reflexo, reprodução. As matérias são refletidas como em um espelho.

\section{Referências}

BAHIA, Juarez. Jornal, história e técnica: as técnicas do jornalismo. 4.ed. São Paulo: Ática, 1990.

BAUDRILLARD, Jean. A transparência do mal: ensaio sobre fenômenos extremos. Campinas: Papirus, 1990. 1991. . Simulacros e simulações. Lisboa: Relógio d'água, Tela-total: mitos e ironias da era virtual e da imagem.
Porto Alegre: Sulina, 1997.

DINES, Alberto. 0 papel do jornal: uma releitura. 6. ed. São Paulo: Summus, 1986.

GUARESCHI, Pedrinho et al. Os construtores da notícia: meios de comunicação, ideologia e ética. Petrópolis: Vozes, 2000.

LÉVY, Pierre. As tecnologias da inteligência: 0 futuro do pensamento na era da informática. Rio de Janeiro: Ed. 34, 1993.

MAFFESOLI, Michel. A contemplação do mundo. Porto Alegre: Artes e Ofícios, 1995.

. A transfiguração do político - a tribalização do mundo. Porto Alegre: Sulina, 1997.

0 tempo das tribos: 0 declínio do individualismo nas sociedades de massa. Rio de Janeiro: Forense-Universitária, 1987.

MANNARINO, Marcus Vinicius Rodrigues. 0 papel do web jornal:veículo de comunicação e sistema de informação. Porto Alegre: Edipucrs, 2000.

MARTINS, Francisco Menezes; SILVA, Juremir Machado da. Para navegar no século XXI. 2. ed. Porto Alegre: Sulina, 2000.

MOUILLAND, Maurice; PORTO, Sérgio Dayrell. 0 jornal: da forma ao sentido. Brasília: Paralelo 15, 1997.

NETO, Antônio Fausto et al (org.). Interação e sentidos no ciberespaço e na sociedade. Porto Alegre: Edipucrs, 2001.

NETO, Antônio Fausto; PINTO, Milton José. 0 indivíduo e as mídias. Rio de Janeiro: Diadorim, 1996.

RUBIM, Antônio Albino Canelas; BENTZ, lone Maria Ghislene; PINTO, Milton José (org.). Comunicação e sociabilidade nas culturas contemporâneas. Petrópolis: Vozes, 1999.

SILVA, Juremir Machado da. A miséria do jornalismo brasileiro: as incertezas da mídia. Petrópolis: Vozes, 2000.

0 pensamento do fim do século. Porto Alegre: LPM, 
1993.

SILVA, Marco. Sala de aula interativa. Rio de Janeiro: Quartet, 2000.

VIRILIO, Paulo. Velocidade e política. São Paulo: Estação Liberdade, 1996. 